\title{
The Impact of Diversity Climate for Women on Female Employees' Intentions to Stay: A Cross-Cultural Study on South Korea and Norway
}

\author{
Hyo-Sook Kim \\ Department of Journalism, Advertising, and PR, Soongsil University, Seoul, Korea \\ Email: khs728@hotmail.com
}

How to cite this paper: Kim, H.-S. (2017) The Impact of Diversity Climate for Women on Female Employees' Intentions to Stay: A Cross-Cultural Study on South Korea and Norway. American Journal of Industrial and Business Management, 7, 1-14. http://dx.doi.org/10.4236/ajibm.2017.71001

Received: October 19, 2016

Accepted: December 31, 2016

Published: January 3, 2017

\section{Copyright $\odot 2017$ by author and} Scientific Research Publishing Inc. This work is licensed under the Creative Commons Attribution International License (CC BY 4.0).

http://creativecommons.org/licenses/by/4.0/

\begin{abstract}
The purpose of this research was to examine what factors influence female workers' intentions to stay with their employer. The effect of diversity climate for women on female employees' intentions to stay was investigated. Also, based on compensation theory, this study hypothesized the moderation effect of a societal culture, especially Hofstede's masculinity-femininity dimension, on the association between diversity climate for women and female employees' intentions to stay. An experiment was conducted to test the hypotheses of this research using South Korea and Norway as study venues. The results revealed that there was a positive association between diversity climate for women and female employees' intentions to stay. Moreover, in the investigation of societal masculinity's moderating role, it was shown that diversity climate for women was highly influential in strengthening the intent to stay for female employees from a masculine society. On the other hand, for those from a feminine society, the impact of diversity climate for women was not as strong as for those from a masculine society. By clarifying the role that a societal culture played in female workers' intentions to stay with their employing organization, the results of this study emphasized the importance of supportive contexts not only at work, but also within a society.
\end{abstract}

\section{Keywords}

Diversity Climate, Women Workforce, Societal Culture, Masculinity-Femininity, Intent to Stay

\section{Introduction}

Raising women workforce rates not only improves gender equality but also helps 
increase and maintain growth rates [1]. Substantial research has shown the importance of attracting and retaining women in the workplace in delivering strong performance at the organizational level, building a strong economy at the national level, and remaining competitive internationally [2] [3] [4] [5] [6]. Responding to this demand of the times, more and more women are working outside of the home. Women's labor force participation rate has increased in OECD countries over the past decades, reaching 57\% in 2012. Even though the number of women in the workforce has been rapidly increasing, many of them opt to quit their jobs, or are forced to, in the middle of their careers [1]. This can lead to the loss of valuable assets for both organizations and female employees.

So far, very few studies have examined what factors influence female workers' intentions to stay with their employing organization. This research tried to address the gap by examining under what conditions female workers decide to remain. More specifically, this study sought to identify how a societal culture's masculinity works in conjunction with diversity climate for women in influencing female employees' intentions to stay. Thus, societal masculinity's moderating role in the positive association between favorable perceptions of diversity climate for women and female employees' intentions to stay was tested. By examining a mechanism through which female workers decide to stay with their employer, this study tried to highlight the importance of supportive contexts not only at the organizational level, but also at the societal level. In order to achieve this goal, this study conducted a 2 (societal culture: masculinity or femininity) by 2 (diversity climate for women: supportive or unsupportive) between-participants factorial design experiment.

\section{Theoretical Framework and Hypotheses}

\subsection{Diversity Climate for Women and Intent to Stay}

Even though diversity seems to be increasingly advocated as an imperative strategic tool that will enhance organizational competitiveness [7], scholars still disagree about the overall effect of diversity [8]. Some scholars maintain that diversity enables an organization to draw talented employees from a larger pool, increases its ability to innovate, and also allows it to better satisfy customer needs [9] [10]. On the other hand, others assert that diversity sometimes leads to less favorable outcomes, such as more conflict, weaker employee attachment, more absenteeism, and more discrimination [11] [12]. However, many scholars agree that more research is needed to find a way to strengthen the potential positive outcomes of diversity while preventing its negative impacts [13]. Many efforts have been exerted for that research. These endeavors have led to the recognition that what is important is not diversity itself, but how to realize the capacity that diversity has in a real organizational setting. This means there are specific environments that make diversity function as a catalyst for positive changes. Many studies have demonstrated that one way of realizing the potentials of diversity is creating and maintaining diversity climate in an organization [14].

Defined as "collective perceptions of the extent to which an organization is 
viewed as having fair employee policies and integrates underrepresented individuals into the work environments" [6], diversity climate can shape the effects of diversity on various organizational performance. For example, a supportive diversity climate is known to reduce in-group bias and social categorization processes, thereby mitigating the negative influence of diversity on performance [8]. On the contrary, an adverse diversity climate may lead to subcultural creation, fragmentation, and other intergroup problems because it tends to highlight similarity-attraction and social categorization processes [11]. At the individual level, a positive diversity climate is linked to many desirable outcomes, such as increased career and organizational commitment, increased job satisfaction, reduced turnover intentions, and lowered absenteeism [8]. At the organizational level, it is positively associated with crucial performance indicators like return on profit, store sales, and customer satisfaction [13].

Among the effects of diversity climate, this research focuses on the impact on employees' perceptions and behaviors. A growing body of literature has demonstrated that an organization's diversity climate can play a significant role in forming employees' perceptions and behaviors toward the organization [15] [16] [17]. Also, of these perceptions and behaviors, the current study chose intentions to stay with an employing organization as a specific behavioral outcome. It is because, in a world where an organization's human capabilities are increasingly the source of its competitive advantage, retaining talent is imperative and voluntary turnover costs can be extensive and damaging to the organization's ability to function [18]. Prior research has produced considerable evidence that a deficient diversity climate can make workers suspicious and weary of their company, hence the workers are willing to break their bonds with their employer [16] [17] [19].

This effect of diversity climate can be applied to the issue of gender diversity. Based on the past definitions of diversity climate, in this research, diversity climate for women was defined as collective perceptions of the extent to which an organization is regarded as integrating female employees into the work environments, and also having fair policies for female employees. Organizations that value gender diversity have an inclusive gender diversity climate that can be expressed by a gender diverse workforce and strong gender diversity management practices [20]. In those organizations, female employees are valued and welcomed in the workplace.

In an organization where a supportive diversity climate for women is established, gender-based social hierarchies become undermined. When gender no longer predicts favored status in an organization, biases based on gender are diminished, thus making female workers want to remain with the organization [5]. In contrast, in an organization with an unsupportive diversity climate for women, female workers are likely to perceive that organizational environment is unfavorable for them because male employees hold a disproportionately large amount of "social value" as members of the preferred social category [21]. This will make female workers want to leave the organization. Based on the concep- 
tualization so far, the first hypothesis was posited.

H1: Favorable perceptions of diversity climate for women are positively associated with female employees' intentions to stay.

\subsection{Societal Culture as a Moderator}

Although it has been shown that a pro-diversity climate has a positive impact on women workforce [5] [21], surprisingly little is known about how those effects occur and which intervening processes and mechanisms are important to explore [13]. Scholars typically depend on moderators to explain the intervening processes and mechanisms. However, only a few of the possible moderators were actually tested [8]. The potential moderators tested thus far include team interdependence [22], complexity of task [23], organizational culture [24], leadership style [25] [26], interpersonal congruence [27], trust [28], distribution of information [29], and diversity beliefs [30].

In this research, societal culture was explored as another possible moderator. It has been commented that a good diversity strategy must address culture change to create a pro-diversity environment that supports diversity and incorporates differences [31] [32]. Also, researchers agree that differences in the women workforce participation rates can be attributed to social norms and culture [1]. Unfortunately, the mechanisms through which societal cultures develop the effects of diversity climate on female workers remain unexplained [32].

As the "collective programming of the mind which distinguishes the members of one human group from another" [33], culture may determine how people and organizations in a specific society react to diversity because it stipulates what behaviors are desirable, accepted, and expected [34]. When investigating culture, it is important to understand the dimensions of culture because dimensions divide culture into a concept, making it easier to understand, measure, and compare across different groups. Also, dimensions of culture affect the behavior of individuals belonging to cultural groups. For this reason, scholars have identified different dimensions of cultures. Among them, the Dutch organizational researcher Geert Hofstede [35] developed a set of five dimensions of culture that have been widely used by management scholars to study the effect of culture on behaviors in organizations and societies. Hofstdede's work has cast a long shadow on business and management research [36], so that his work has become the yardstick against which new research on cultural differences is validated [37].

Hofstede [35] identified five key cultural dimensions. Using these dichotomous continua of a societal culture, Hofstede assigned a comparative score on each of these five dimensions across the countries that he studied. Hofstede's first dimension is the continuum between individualism and collectivism, which consistently differentiates Eastern from Western cultures. The second dimension is uncertainty avoidance, which refers to the extent to which a society can tolerate ambiguity. The third is masculinity-femininity, which addresses the value society attaches to social roles based on gender. Hofstede measured the extent to 
which people of both sexes in a culture endorse masculine or feminine traits. The fourth dimension, power distance, refers to the extent to which wealth, power, and prestige are distributed disproportionately among people in different social strata or classes. Finally, long-term orientation, which was newly added using a questionnaire designed by Chinese scholars, measures the extent to which people fosters virtues related to the future or virtues related to the past and present.

Among these dimensions, this research focused on the "masculinity-femininity" dimension, which has a logical and intervening link with diversity climate for women. Using the masculinity-femininity dimension, Hofstede [35] measured the extent to which masculine traits are prevailing in societies. Generally, masculine values include assertiveness, quest for material wealth, lack of concern for diversity, emphasis on career success, belief in the inequality of women, paternalism, and competitiveness. In contrast, feminine-oriented cultures place value on people, quality of life, gender equality, environmental awareness, and nurturance. Also, in masculine societies, there is a larger gender wage gap and fewer women are in management. In addition, a preference is given to higher pay. On the other hand, feminine societies have smaller gender wage gaps and preference for fewer working hours. Furthermore, there are more women in management.

Although positive perceptions of diversity climate for women are generally expected to lead to greater probabilities of female workers' intentions to stay with their employer, this study propose that this expectation can differ for masculine versus feminine cultures. That is, this relationship can be stronger for masculine societies than for feminine societies. More specifically, female workers in a masculine society benefit more from the existence of a strong organizational climate for gender diversity, while female workers in a feminine society are less affected by it.

The theoretical reasoning for this proposition is grounded on compensation theory [17] [38]. Compensation theory maintains, when people experience a lack of a resource in one domain, "they turn their focus to the other domain" [17] to make up for the missing resource. For example, Singh and Selvarajan [17] convincingly showed that for employees hailing from a community with an unsupportive diversity climate, a supportive organizational diversity climate was greatly instrumental in reinforcing their intentions to remain with their employing organization.

Extant research has mainly applied compensation theory to domains such as work, family, and community [38] [39] [40]. However, the researcher thought that the theory can be extended to be used in a broader context, for example, society. Thus, when female workers cannot experience a favorable diversity climate in the overall society, they may shift their focus toward their organization where a diversity climate is highly supportive. As a result, when perceiving a favorable diversity climate for women at work, female workers may be more willing to continue to work for their current employer. 
Female workers in masculine societies are expected to express significantly decreased turnover intentions when they perceive a favorable diversity climate for women in their organization because they know they will encounter an adverse diversity climate outside the organization. In a masculine society, where intolerance for diversity plays a dominant role, female workers know that they may be discriminated against in other organizations. They know that they may be subjected to a lack of concern for diversity, inequality, and bias against women within the overall society. In contrast, in a feminine society, organizational diversity climate for women may exhibit less influence on female workers' intentions to stay with an employing organization because the overall level of tolerance for gender diversity is already high in the society. Based on the discussion thus far, the second hypothesis was developed.

H2: Societal masculinity will moderate the positive association between favorable perceptions of diversity climate for women and female employees' intentions to stay, such that the above relationship is stronger when the perceived societal culture is more masculine than feminine.

\section{Method}

\subsection{Selection of Countries}

To test the hypotheses, a 2 (societal culture: masculine or feminine) by 2 (diversity climate for women: strong or weak) between-participants factorial design experiment was conducted. The experiment design is provided in Table 1.

For this study, it was important to identify each of a masculine society and a feminine society. Referring to Hofstede's [35] research results, South Korea and Norway were chosen as two study venues. In Hofstede's 2001 study, South Korea was a society with high power distance and low tolerance of uncertainty. Also, it was masculine and collectivistic. On the other hand, Norway's societal culture was very feminine and individualistic. It was also a society with low power distance and moderate tolerance of uncertainty.

The two countries were mainly chosen because women's labor force participation rates in the countries are in the stark contrast. The female labor participation rate in South Korea is $55 \%$, which is $22 \%$ lower than that of males. South Korean women drop out of the labor force at a much higher rate when they marry or have children, thereby leading to a $15 \%$ drop in their $30 \mathrm{~s}$. Also, South Korea ranks the worst among the 33 OECD countries in wage disparity, with a $39 \%$ gap between men and women in medial wages. Moreover, there is an unequal representation of women, especially in high-profile positions such as

Table 1. Experimental design.

\begin{tabular}{ccc}
\hline \multirow{2}{*}{$\begin{array}{c}\text { Diversity climate } \\
\text { for women }\end{array}$} & \multicolumn{2}{c}{ Societal culture } \\
\cline { 2 - 3 } & Masculine culture (South Korea) & Feminine culture (Norway) \\
\hline Supportive & $\mathrm{N}=25$ & $\mathrm{~N}=25$ \\
Unsupportive & $\mathrm{N}=25$ & $\mathrm{~N}=25$ \\
\hline
\end{tabular}


legislators, senior officials, and managers. The female to male worker ratio in upper management positions and public office is a paltry one to nine, which ranks South Korea $104^{\text {th }}$ in the world, behind some of the world's least developed countries [1].

Meanwhile, $76 \%$ of Norway's working-age women are on the job with only a slightly lower representation than men. Women's mean earnings are approximately $85 \%$ of men's, which makes the gender income gap in Norway remain relatively stable. Also, women accounts for about $40 \%$ of Norwegian boardroom seats [1]. Because this research intended to delve into the main reasons for female workers' turnover intentions, the big gap in female labor participation rates between the two countries could justify the choice of the study venues.

A $t$-test was conducted to check whether the level of masculinity-femininity in the two societies was statistically significantly different. Twenty people from each country participated in a survey, indicating how much they agreed on the following statement on a 7-point Likert scale ranging from 1 (strongly disagree) to 7 (strongly agree): "This country places a value on diversity, quality of life, gender equality, environmental awareness and nurturance." The result showed that the mean difference between Norway $(M=5.71, S D=1.10)$ and South Korea $(M=3.17, S D=1.08)$ was statistically significant $(t=5.43, p<.01)$.

\subsection{Participants}

To test the hypotheses, in total of 100 female MBA students from one university located in Seoul and another university located in Oslo, hence 50 students from each university, participated in the experiment. Many studies have indicated that MBA students are suitable management research participants because they have a high possibility of working at companies in the near future [41]. In this research, it was also important not to use current employees because their perceptions of the employing organizations could influence the research results. The mean ages of the participants were 26.32 years $(S D=5.84)$ for the South Korean university and 27.35 years $(S D=6.56)$ for the Norwegian university. The participants in the two countries were randomly assigned to two diversity climate conditions (supportive or unsupportive), with 25 participants per cell. To fulfill the university institutional review board requirements, the participants were given an opportunity to decline participation if they did not want to take part in the experiment. No participant declined inclusion in the study. Informed consent was obtained from all individual participants included in the study. The participants received extra credit for taking part in the experiment.

\subsection{Manipulation of Independent Variables}

Participants in Seoul and Oslo, respectively, were provided with information about the diversity climate for women in hypothetical companies. Based on previous research on diversity climate for women [6] [17], two scenarios were developed. Each scenario was written as if it described a fictitious company's working environment. 
A supportive diversity climate for women was described as employees' collective perceptions of the extent to which an organization is regarded as: 1) treating women employees fairly, 2) maintaining a diversity-friendly work environment, 3 ) providing adequate networking and training opportunities for women, and 4) ensuring that women are not overlooked in promotion decisions. An unsupportive diversity climate for women was described as the opposite of the above descriptions. To increase the ecological validity of the experiment, information on the two types of diversity climate was provided in the form of newspaper articles [42]. The newspaper articles were written in the format of investigative reports describing the fictitious companies' working environments. In the course of material development, judge panels, composed of faculty and graduate students, were invited to review and revise the stimuli.

\subsection{Dependent Variable Measures: Intent to Stay}

This research employed Singh and Selvarajan's [17] measures to assess intent to stay. The three-item scale demonstrated an alpha reliability of $0.82(\alpha=.82)$. Unlike turnover intention measures, Singh and Selvarajan's scale measured employees' intentions to stay with their current employer and is positively worded. Sample items from this scale are: "Under no circumstances I would voluntarily leave this organization," "I plan to stay in this organization for as long as possible." The items were measured on a 7-point Likert-type scale ranging from 1 (strongly disagree) to 7 (strongly agree).

\subsection{Procedure}

All the scenarios and measures were translated into Korean and Norwegian respectively using a parallel-translation method [36]. In the parallel-translation method, more than two translators participate in back translation, and the results are compared, differences discussed, and the most suitable translation is selected. Furthermore, pretests were conducted to assure the appropriateness of translation.

In the experiment, the participants were told that the researcher was interested in female workers' perceptions of working environments. The participants were asked to assume that they were employed by a fictitious company in each country. Then, they received one-page information sheets describing each of the companies. Fictitious news articles describing the experimental conditions were attached on the next page. The participants read the experimental stimuli and they completed the dependent measures and a manipulation check item at their own pace. Then, they were debriefed. In the debriefing, they learned that the information they read about the companies was prepared only for research purposes.

\section{Results}

\subsection{Manipulation Check}

A $t$-test was run to determine if the manipulation worked as intended. To check 
the appropriateness of the diversity climate variable manipulation, based on Rabl and Triana's [20] study, the following question was asked on a 7-point Likerttype scale ranging from 1 (very unsupportive attitude) to 7 (very supportive attitude): "In your opinion, which attitude does this company have toward gender diversity?" A $t$-test revealed that there was a significant difference between the supportive diversity climate for women and the unsupportive diversity climate for women ( $M=5.87, M=2.37$ respectively, $p<0.01)$.

\subsection{Hypothesis Tests}

The means and standard deviations of the participants' intentions to stay are provided in Table 2.

To test the hypotheses, a two-way ANOVA was conducted. The data were analyzed according to a $2 \times 2$ between-participants factorial design. The results of the ANOVA test are reported in Table 3.

First, as postulated in $\mathrm{H} 1$, diversity climate's main effect was statistically significant $(F=31.68, p<0.01)$. This means the participants revealed more intentions to stay when the diversity climate for women was supportive than when it was unsupportive. Thus, hypothesis 1 was accepted.

Also, consistent with $\mathrm{H} 2$, a two-way interaction of diversity climate and societal culture was observed where societal culture moderated the impact of diversity climate for women on intentions to stay $(F=18.94, p<0.05)$. The participants showed more intent to stay in the masculine society than in the feminine society when diversity climate for women was supportive. The gap between the supportive diversity climate and the unsupportive diversity climate in the feminine society $\left(M_{\text {supportive-diversity }}=4.97\right.$ versus $\left.M_{\text {unsupportive-diversity }}=3.12\right)$ was not as big as the one in the masculine society $\left(M_{\text {supportive-diversity }}=5.85\right.$ versus $M_{\text {unsuppor- }}$ tive-diversity $=3.24)$. Thus, hypothesis 2 was also accepted. This interaction effect between diversity climate and societal culture is shown in Figure 1.

Table 2. The means and standard deviations of intent to stay $(n=100)$.

\begin{tabular}{llclc}
\hline & \multicolumn{2}{c}{ Masculine culture } & \multicolumn{2}{c}{ Feminine culture } \\
\cline { 2 - 5 } & $M$ & $S D$ & $M$ & $S D$ \\
\hline Strong diversity climate & 5.85 & 0.97 & 4.97 & 1.12 \\
Weak diversity climate & 3.24 & 1.02 & 3.12 & 0.98 \\
\hline
\end{tabular}

Table 3. Analysis of variance effects on intent to stay.

\begin{tabular}{ccccc}
\hline Source & Sum of squares & $d f$ & $M S$ & $F$ \\
\hline Diversity climate (A) & 46.88 & 1 & 46.88 & $31.68^{* *}$ \\
Societal culture (B) & 3.14 & 1 & 3.14 & 2.12 \\
A $\times$ B & 18.94 & 1 & 18.94 & $12.80^{*}$ \\
Total & & 99 & & \\
\hline
\end{tabular}

${ }^{* *} \mathrm{p}<0.01,{ }^{*} \mathrm{p}<0.05$ 


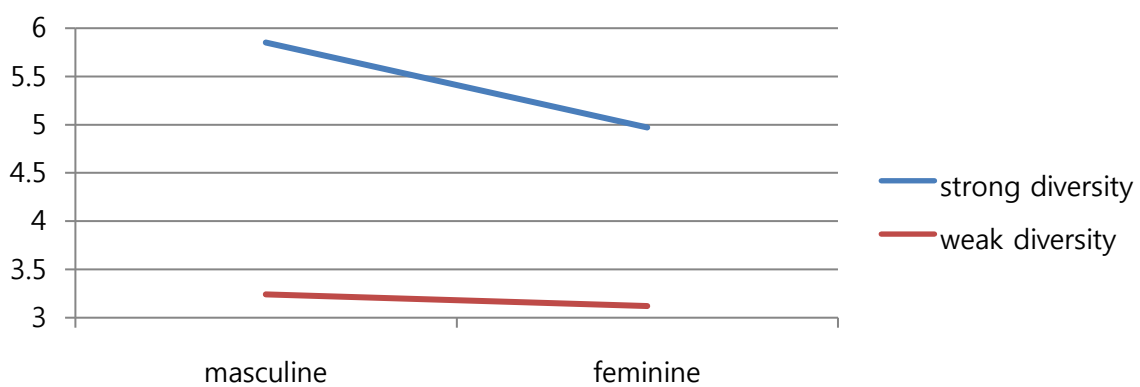

Figure 1. Two-way interaction of diversity climate and societal culture.

\section{Discussion}

The purpose of this study was to examine the association between diversity climate for women and female workers' intentions to stay with their employer. Also, this research tried to test the moderation effect of societal culture, especially Hofstede's masculinity-femininity dimension, on the association between the diversity climate for women and female workers' intentions to stay. The followings are the main research findings. First, it was revealed that there was a positive relationship between a supportive diversity climate for women and female workers' intentions to stay. Second, in the investigation of societal masculinity's moderating role, it was shown that a supportive diversity climate for women was highly influential in strengthening the intent to stay for the participants from the masculine society. On the other hand, for those participants from the feminine society, the impact of societal culture was not as strong as for those from the masculine society.

\subsection{Implications for Theory and Practice}

The findings of this study made theoretical contributions. First, this study showed the importance of diversity climate for women in influencing female workers' intentions to stay. This result is in consistent with extant research [5] [16] [17], thus strengthening the arguments about the association between an organizational diversity climate and employee retention. Second, this research reaffirmed compensation theory. Compensation theory has been recognized as an important work-nonwork mechanism that explained well how individuals compensate for their dissatisfaction in one domain with satisfaction in another domain. Thus far, the existing research on the work-nonwork interface has mainly tested rather limited contexts, such as work, family, and community. This study contributed to expanding the theory's scope to a broader context by choosing societal culture as a possible domain. The results of this study emphasized the importance of supportive contexts not only at work, but also within the society. Third, this study responded to calls for research on the moderators of the link between diversity climate and employees' behavioral outcomes. There has been far less research about the processes and mechanisms through which diversity climate impacts employees' perceptions and behaviors. Therefore, conducting a study on societal culture as a possible moderator of the link con- 
tributed to filling the gap in the diversity climate research.

This study also has practical implications. First, this research reassured the significance of diversity climate for women in convincing female employees to stay with their organization. As many studies have reported, just putting people together who differ in demographic characteristics, by itself, cannot create a diversity climate [18]. To cultivate a supportive diversity climate for women, organizations might consider developing strategies, such as introducing and applying gender-diversity friendly HR policies, practices, and procedures with regard to recruiting, career development, or promotion. Second, this study also showed the importance of a supportive organizational diversity climate as a compensator for a poor societal diversity climate. The compensating role of an organizational diversity climate in workplaces is of greater importance in a masculine society where a concern for diversity is lacking. Societal culture cannot be changed in a short period of time. Many scholars have maintained that changes in culture are not easy [43]. However, it is much easier to innovate in an organizational climate. Thus, organizations in a masculine society will have to pay more attention to diversity climate if they want to recruit and retain women for their workforce.

\subsection{Limitations and Future Research Directions}

Needless to say, experimental research does have some disadvantages. The scope of this study is limited to the experimental setting. The readers should be advised not to interpret the findings of this study beyond what was found in the experiment. Thus, a next logical step would be to conduct research using other more generalizable research methods in more diverse settings.

Also, in this research, only a couple of variables could be tested to analyze female employees' intentions to stay. Obviously, there can be more factors that influence their intentions. For example, government policies may contribute to shaping female employees' intentions to stay. Indeed, government policy has made a difference in many northern European countries. For instance, the Norwegian government has established a highly subsidized child care system, a comprehensive parental leave policy, and a firm policy of shorter working hours for women [1], which helped engender today's high female labor participation rate and birth rate. Thus, more research is needed to identify those other possible factors.

It should be acknowledged that the distinctions of the main variables, diversity climate and societal culture, are less clear in the real world. Hofstede [16] used continua to distinguish societal cultures. Furthermore, diversity climate can be calculated using measurement items. Future studies may fruitfully explore the limits of this research by examining the varying degrees of the key variables identified in the present study. Also, this research focused on only one aspect of societal culture, which was masculinity-femininity. Other cultural dimensions may influence female workers' perceptions and behaviors. Thus, another research direction will be to explore the impact of other cultural dimensions. 


\section{References}

[1] Easton, N. (2015) Why Aren't There More Women in the Workforce? http://www.fortune.com

[2] Ali, M., Ng, Y.L. and Kulik, C.T. (2014) Board Age and Gender Diversity: A Test of Competing Linear and Curvilinear Predictions. Journal of Business Ethics, 125, 497-512. https://doi.org/10.1007/s10551-013-1930-9

[3] Boulouta, I. (2013) Hidden Connections: The Link between Board Gender Diversity and Corporate Social Performance. Journal of Business Ethics, 113, 185-197. https://doi.org/10.1007/s10551-012-1293-7

[4] Broderick, E. (2012) Women in the Workforce. The Australian Economic Review, 45, 204-210. https://doi.org/10.1111/j.1467-8462.2012.00682.x

[5] Nishii, L.H. (2013) The Benefits of Climate for Inclusion for Gender-Diverse Groups. Academy of Management Journal, 56, 1754-1774. https://doi.org/10.5465/amj.2009.0823

[6] Virick, M. and Greer, C.R. (2012) Gender Diversity in Leadership Succession: Preparing for the Future. Human Resource Management, 51, 575-600. https://doi.org/10.1002/hrm.21487

[7] Cooke, F.L. and Saini, D.S. (2010) Diversity Management in India: A Study of Organizations in Different Ownership Forms and Industrial Sectors. Human Resource Management, 49, 477-500. https://doi.org/10.1002/hrm.20360

[8] Gonzalez, J.A. and DeNisi, A.S. (2009) Cross-Level Effects of Demography and Diversity Climate on Organizational Attachment and Firm Effectiveness. Journal of Organizational Behavior, 30, 21-40. https://doi.org/10.1002/job.498

[9] Cox, T.H. and Blake, S. (1991) Managing Cultural Diversity: Implications for Organizational Competitiveness. The Executive, 5, 45-56. https://doi.org/10.5465/AME.1991.4274465

[10] Richard, O.C., Barnett, T., Dwyer, S. and Chadwick, K. (2004) Cultural Diversity in Management, Firm Performance, and the Moderating Role of Entrepreneurial Orientation Dimensions. Academy of Management Journal, 47, 255-266. https://doi.org/10.2307/20159576

[11] Sacco, J.M. and Schmitt, N. (2005) A Dynamic Multilevel Model of Demographic Diversity and Misfit Effects. Journal of Applied Psychology, 90, 203-231. https://doi.org/10.1037/0021-9010.90.2.203

[12] Tsui, A.S. and Gutek, B. (1999) Demographic Differences in Organizations: Current Research and Future Directions. Lexington Books, Lanham.

[13] Boehm, S.A., et al. (2014) Expanding Insights on the Diversity Climate-Performance Link: The Role of Workgroup Discrimination and Group Size. Human Resource Management, 53, 379-402. https://doi.org/10.1002/hrm.21589

[14] Holvino, E.H., Ferdman, B.M. and Merrill-Sands, D. (2004) Creating and Sustaining Diversity and Inclusion in Organizations: Strategies and Approaches. In: Stockdale, M.S. and Cosby, F.J., Eds., The Psychology and Management of Workplace Diversity, Blackwell, Malden, 245-276.

[15] Hicks-Clarke, D. and Iles, P. (2000) Climate for Diversity and Its Effects on Career and Organizational Attitudes and Perceptions. Personnel Review, 29, 324-345. https://doi.org/10.1108/00483480010324689

[16] McKay, P.F., et al. (2007) Racial Differences in Employee Retention: Are Diversity Climate Perceptions the Key? Personnel Psychology, 60, 35-62. https://doi.org/10.1111/j.1744-6570.2007.00064.x 
[17] Singh, B. and Selvarajan, T.T. (2013) Is It Spillover or Compensation? Effects of Community and Organizational Diversity Climates on Race Differentiated Employee Intent to Stay. Journal of Business Ethics, 115, 259-269. https://doi.org/10.1007/s10551-012-1392-5

[18] Kaplan, D.M., Wiley. J.W. and Maertz Jr., C. (2011) The Role of Calculative Attachment in the Relationship between Diversity Climate and Retention. Human Resource Management, 50, 271-287. https://doi.org/10.1002/hrm.20413

[19] Foley, S., Kidder, D.L. and Powell, G.N. (2002) The Perceived Glass Ceiling and Justice Perceptions: An Investigation of Hispanic Llaw Associates. Journal of Management, 28, 471-496. https://doi.org/10.1177/014920630202800401

[20] Rabl, T. and Triana, M.C. (2014) Organizational Value for Age Diversity and Potential Applicants' Organizational Attraction: Individual Attitudes Matter. Journal of Business Ethics, 121, 403-417. https://doi.org/10.1007/s10551-013-1729-8

[21] Brewer, M.B. (1999) The Psychology of Prejudice: In-Group Love or Out-Group Hate? Journal of Social Issues, 55, 429-444. https://doi.org/10.1111/0022-4537.00126

[22] Timmerman, T.A. (2000) Racial Diversity, Age Diversity, Interdependence, and Team Performance. Small Group Research, 31, 592-606. https://doi.org/10.1177/104649640003100505

[23] Pelled, L.H., Eisenhardt, K.M. and Xin, K.R. (1999) Exploring the Black Box: An Analysis of Work Group Diversity, Conflict and Performance. Administrative Science Quarterly, 44, 1-28. https://doi.org/10.2307/2667029

[24] Jehn, K.A. and Bezrukova, K. (2004) A Field Study of Group Diversity, Work Group Context, and Performance. Journal of Organizational Behavior, 25, 703-729. https://doi.org/10.1002/job.257

[25] Kearney, E. and Gebert, D. (2009) Managing Diversity and Enhancing Team Outcomes: The Promise of Transformational Leadership. Journal of Applied Psychology, 94, 77-89. https://doi.org/10.1037/a0013077

[26] Shin, S.J. and Zhou, J. (2007) When Is Educational Specialization Heterogeneity Related to Creativity in Research and Development Teams? Transformational Leadership as a Moderator. Journal of Applied Psychology, 92, 1709-1721. https://doi.org/10.1037/0021-9010.92.6.1709

[27] Polzer, J.T., Milton, L.P. and Swarm, W.B. (2002) Capitalizing on Diversity: Interpersonal Congruence in Small Work Groups. Administrative Science Quarterly, 47, 296-324. https://doi.org/10.2307/3094807

[28] Olson, B.J., Parayitam, S. and Bao, Y. (2007) Strategic Decision Making: The Effects of Cognitive Diversity, Conflict, and Trust on Decision Outcomes. Journal of Management, 33, 196-222. https://doi.org/10.1177/0149206306298657

[29] Kooij-de Bode, H.J., van Knippenberg, D. and van Ginkel, W.P. (2008) Ethnic Diversity and Distributed Information in Group Decision Making: The Importance of Information Elaboration. Group Dynamics: Theory, Research, and Practice, 12, 307-320. https://doi.org/10.1037/1089-2699.12.4.307

[30] Van Knippenberg, D., Haslam, S.A. and Platow, M. (2007) Unity through Diversity: Value-in-Diversity Beliefs, Work Group Diversity, and Group Identification. Group Dynamics: Theory, Research, and Practice, 11, 207-222. https://doi.org/10.1037/1089-2699.11.3.207

[31] Avery, D.R. and McKay, P.F. (2010) Doing Diversity Right: An Empirical Based Approach to Effective Diversity Management. In: Hodgkinson, G.P. and Ford J.K., Eds., International Review of Industrial and Organizational Psychology, John Wiley \& Sons, Chichester, 227-252. https://doi.org/10.1002/9780470661628.ch6 
[32] Guillaume, Y.R.F., Dawson, J.F., Woods, S.A., Sacramento, C.A. and West, M.A. (2013) Getting Diversity at Work to Work: What We Know and What We Still Don't Know. Journal of Occupational and Organizational Psychology, 86, 123-141. https://doi.org/10.1111/joop.12009

[33] Hofstede, G. (1984) Culture's Consequences: International Differences in WorkRelated Values. Sage, Beverly Hills.

[34] Van der Vegt, G.S., van de Vliert, E. and Huang, X. (2005) Location-Level Links between Diversity and Innovative Climate Depends on National Power Distance. Academy of Management Journal, 48, 1171-1182. https://doi.org/10.5465/AMJ.2005.19573116

[35] Hofstede, G. (2001) Culture's Consequences: Comparing Values, Behaviors, Institutions, and Organizations across Nations. Sage, Thousand Oaks.

[36] Weeks, W.A., Loe, T.W., Chonko, L.B., Martinez, C.R. and Wakefield, K. (2006) Cognitive Moral Development and the Impact of Perceived Organizational Ethical Climate on the Search for Sales Force Excellence: A Cross-Cultural Study. Journal of Personal Selling \& Sales Management, 26, 205-217. https://doi.org/10.2753/PSS0885-3134260207

[37] Triandis, H.C. (2004) The Many Dimensions of Culture. Academy of Management of Executive, 18, 88-93. https://doi.org/10.5465/AME.2004.12689599

[38] Edwards, J.R. and Rothbard, N. (2000) Mechanisms Linking Work and Family: Clarifying the Relationship between Work and Family Constructs. Academy of Management Review, 25, 178-199.

[39] Burke, R.J. and Greenglass, E.R. (1987) Work and Family. In: Cooper, C.L. and Robertson, I.T., Eds., International Review of Industrial and Organizational Psychology, Wiley, New York, 273-320.

[40] Zedeck, S. (1992) Introduction: Exploring the Domain of Work and Family Concerns. In: Zedeck, S., Ed., Work, Families, and Organizations, Jossey Bass, San Francisco, 1-32.

[41] Rajasekar, J. and Simpson, M. (2014) Attitudes toward Business Ethics: A GenderBased Comparison of Business Students in Oman and India. Journal of Leadership, Accountability and Ethics, 11, 99-114.

[42] Renkema, J. and Hoeken, H. (1998) The Influence of Negative Newspaper Publicity on Corporate Image in the Netherlands. The Journal of Business Communication, 35, 521-535. https://doi.org/10.1177/002194369803500405

[43] Kroeber, A.L. and Kluckhohn, C. (1952) Culture: A Critical Review of Concepts and Definitions. Harvard University, Cambridge. 
Submit or recommend next manuscript to SCIRP and we will provide best service for you:

Accepting pre-submission inquiries through Email, Facebook, LinkedIn, Twitter, etc. A wide selection of journals (inclusive of 9 subjects, more than 200 journals)

Providing 24-hour high-quality service

User-friendly online submission system

Fair and swift peer-review system

Efficient typesetting and proofreading procedure

Display of the result of downloads and visits, as well as the number of cited articles Maximum dissemination of your research work

Submit your manuscript at: http://papersubmission.scirp.org/

Or contact ajibm@scirp.org 